\title{
Communication \\ Adsorption of Gas-Phase Cyclohexanone on Atmospheric Water Films
}

\author{
Shangpeng Hao ${ }^{1}$, Chao Sun ${ }^{1}$, Yuanpeng Zhang ${ }^{1}$, Haitao Wang ${ }^{1, *}$, Wenbo Zhao ${ }^{1}$, Xiaolu Wang ${ }^{2}$ and Jinghai Li ${ }^{3}$ \\ 1 State Key Laboratory of NBC Protection for Civilian, Beijing 102205, China; hsp199199@163.com (S.H.); \\ 071022047@fudan.edu.cn (C.S.); zyuanp@mail.ustc.edu.cn (Y.Z.); zhaowb1987@126.com (W.Z.) \\ 2 Department of Automation, Tsinghua University, Beijing 100084, China; wangxlu@mail.tsinghua.edu.cn \\ 3 Nanjing Buyiren Information Technology Co., Ltd., Nanjing 210046, China; ljhai725@163.com \\ * Correspondence: dr_wht@163.com
}

check for updates

Citation: Hao, S.; Sun, C.; Zhang, Y.; Wang, H.; Zhao, W.; Wang, X.; Li, J.

Adsorption of Gas-Phase

Cyclohexanone on Atmospheric Water Films. Atmosphere 2021, 12, 1705. https://doi.org/10.3390/ atmos12121705

Academic Editors: Adrianos Retalis, Vasiliki Assimakopoulos and Kyriaki-Maria Fameli

Received: 19 November 2021 Accepted: 16 December 2021 Published: 20 December 2021

Publisher's Note: MDPI stays neutral with regard to jurisdictional claims in published maps and institutional affiliations.

Copyright: (c) 2021 by the authors. Licensee MDPI, Basel, Switzerland. This article is an open access article distributed under the terms and conditions of the Creative Commons Attribution (CC BY) license (https:/ / creativecommons.org/licenses/by/ $4.0 /)$.

\begin{abstract}
The fate of atmospheric volatile organic compounds (VOCs) strongly depends on the partitioning processes on the surface of aerosols, which are coated with a thin water film. However, the behavior of VOCs in the aqueous film of aerosols is difficult to measure. In this work, the interfacial partition constant of cyclohexanone was determined using a novel flow-tube reactor. A thin, aqueous film placed in the reactor was exposed to cyclohexanone gas. The subsequent partitioning was measured using chromatography techniques. The quality control tests were first conducted to ensure the accuracy of the adsorption experiments. The cyclohexanone concentration was then plotted as a function of film thickness to obtain the partitioning constants. As the thickness of the water film decreased, the aqueous concentration of cyclohexanone increased, indicating that surface adsorption played a dominant role in the uptake of cyclohexanone. According to the temperature dependence of the interfacial partition constant, the solvation enthalpy and entropy of cyclohexanone were obtained. The results of this study would help to elucidate the effect of atmospheric water film on the gas-aerosol partitioning of VOCs, and thus can help to better understand the fate of VOCs in the atmosphere.
\end{abstract}

Keywords: cyclohexanone; air-water interface; partition constant; solvation enthalpy and entropy

\section{Introduction}

Cyclohexanone is one of the most commonly used industrial raw materials [1,2]. It can be found in the synthesis process of nylon, caprolactam, adipic acid, etc. Cyclohexanone is also a form of widely used solvent for dissolving cellulose, acetate resins, vinyl resins, rubbers, and waxes [3]. The toxicity of cyclohexanone is moderate from inhalation and skin contact. In animals, a high concentration of gas-phase cyclohexanone can cause central nervous system depression, stupor, hyper- or hypoactivity, ataxia, and convulsive movements [4]. As a form of volatile organic compound (VOC), cyclohexanone is emitted into the atmosphere in large quantities every year [5-8]. The distribution of cyclohexanone between air-bulk water or other mixtures has been reported $[9,10]$. However, the effect of atmospheric aerosols on its diffusion has not yet been assessed.

Atmospheric water films on aerosol particles, such as fog, mist, dew, cloud droplets, etc., are the largest air-water interface in the atmosphere [11]. The fate of atmospheric VOCs such as cyclohexanone strongly depends on the partitioning processes between air and water [12-14]. Generally, cyclohexanone is first adsorbed at the gas-water interface, and further dissolved into the aqueous phase of aerosols in the transport process. Similar to Henry's law constant, the interfacial adsorption of organic compounds can be described by the air-water interface partition constant, which depends on the polarity and size of the target molecule and the polarity of the film surface [15].

To elucidate the significance of the air-water interface in the atmospheric fate and transport of cyclohexanone vapor, the air-water interface partition constant is required. 
The objective of this work was to obtain the partition constant of cyclohexanone. The uptake enthalpy and entropy were also obtained with the same apparatus.

\section{Materials and Methods}

\subsection{Chemicals and Materials}

Chemicals used in this study included: cyclohexanone (analytically pure, Sinopharm Chemical Reagent, Shanghai, China), $\mathrm{NaOH}$ (chromatographic pure, Beijing Chemical Manufacturer, Beijing, China), nitrogen and air (99.999\%, products of Beijing Haipu Gas Industry, Beijing, China), and high purity hydrogen, produced by a hydrogen generator (99.999\%, Beijing Beifen Kehuan Instrument, Beijing, China). All these gases were purified by being passed through silica gel, $5 \mathrm{~A}$ molecular sieves and active carbon before use. The aqueous solution of cyclohexanone was made using Milli-Q water $(18.5 \mathrm{~m} \Omega \mathrm{cm}$, Gaosen instrument equipment, Shanghai, China).

\subsection{Method and Apparatus}

There are various experimental methods for determining interfacial partition constants, and a commonly used method for the adsorption of gas-phase cyclohexanone on atmospheric water films is based on a flow-tube reactor technique described by Chen et al. [15-17]. The cyclohexanone concentration in the water films was accumulated by both adsorption and absorption processes, which can be described by the following equation:

$$
C_{W}^{T}=C_{W}+C_{g} \frac{K_{A I}}{\delta}
$$

where $C_{w}^{T}$ is the overall equilibrium concentration for cyclohexanone, $C_{w}$ is the bulk water phase concentration of cyclohexanone, $C_{g}$ is the concentration in the gas phase, $\delta$ is the thickness of water film, and $\mathrm{K}_{\mathrm{AI}}$ is the partition constant at the air-water interface. Divide both sides by $\mathrm{C}_{\mathrm{g}}$, and the equation can be rewritten as:

$$
\mathrm{K}_{\mathrm{WA}}^{*}=\mathrm{K}_{\mathrm{WA}}+\frac{\mathrm{K}_{\mathrm{AI}}}{\delta}
$$

where $\mathrm{K}_{\mathrm{WA}}^{*}$ is a composite of the bulk water-air partition constant, and $\mathrm{K}_{\mathrm{WA}}$ is the conventional Henry's constant, which describes the equilibrium relationship between bulk air and bulk water. When the film thickness tends to be infinitely large, the interfacial partitioning is negligible. However, when the value of $\delta$ is small, the partition in the air-water interface cannot be ignored.

The adsorption experiments performed with the flow-tube reactor are shown in Figure 1. The reactor was optimized based on the published work [15-17], including a half-circular visible Plexiglas tube, a 316 stainless steel body, a rectangular quartz trough, sealing parts, and sensors. Thin film water was placed on the bottom surface of the rectangular quartz boat (length $490 \mathrm{~mm}$, width $30 \mathrm{~mm}$, and height $5 \mathrm{~mm}$ ) and exposed to cyclohexanone vapor during the experiment. The inner surface of the glass tube was attached with a PTFE film to prevent the adsorption of cyclohexanone [18]. To improve stability and reproducibility, three types of sensors were used for the accurate measurements of temperature, pressure, and humidity in the reactor. Coolant circulators were used to control the coolant temperature in the range of $247 \mathrm{~K}$ to $373 \mathrm{~K}$. A mixture of glycol (50\%) and water $(50 \%)$ was used as a coolant and was circulated in the reactor to maintain the temperature of the water film.

Nitrogen was used as the carrier gas at a flow rate of $150 \mathrm{~mL} \cdot \mathrm{min}^{-1}$. The flow rate was controlled by a SY-9312D mass flow controller (MFC, range $0-500 \mathrm{~mL} \cdot \mathrm{min}^{-1}$, ShengYe Technology Company of Beijing, Beijing, China). To avoid the volatilization of the water film during the experiment, the carrier gas was humidified by passing through a vessel containing deionized water. The temperature of the vessel was kept consistent with the temperature of the water film to avoid the condensation of the water vapor. 


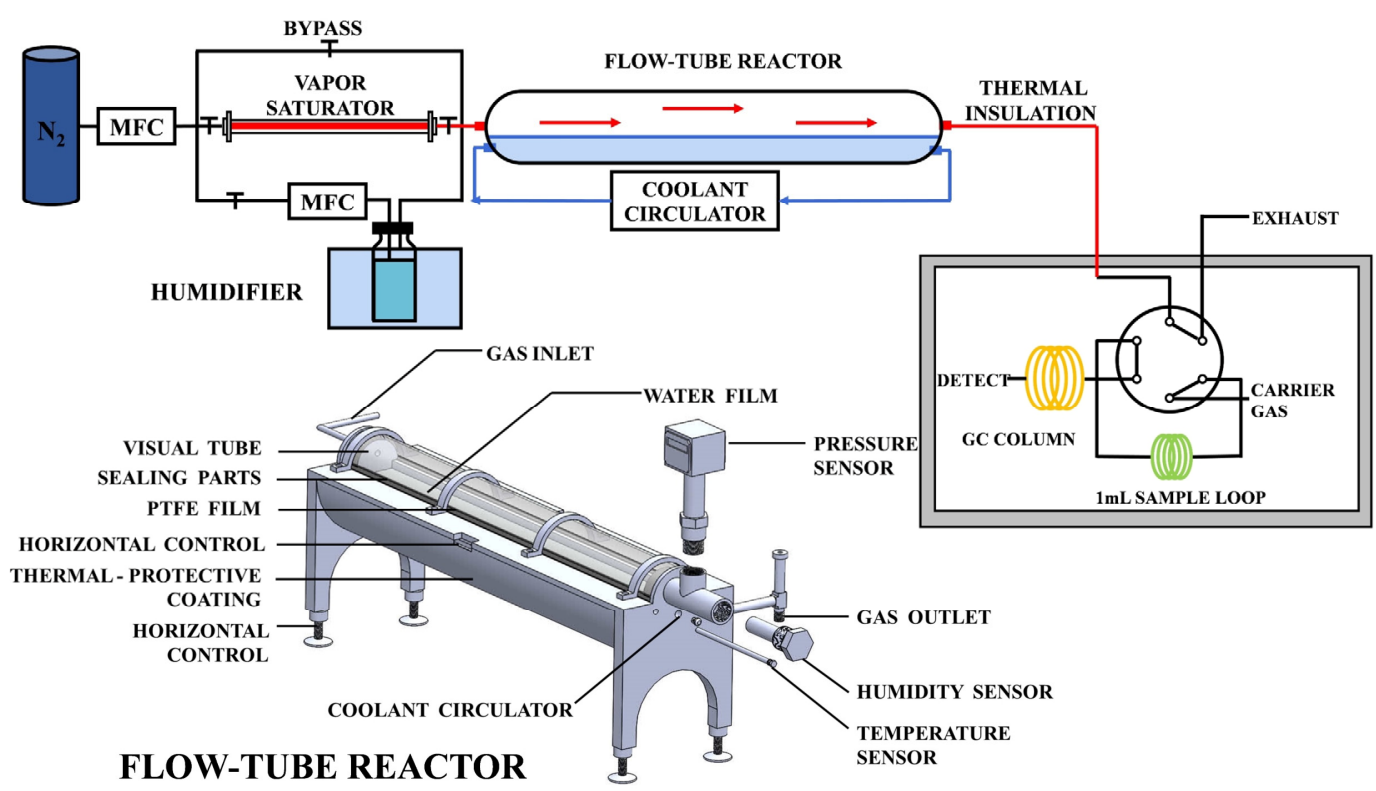

Figure 1. Flow-tube reactor for uptake experiments of cyclohexanone onto thin water films.

The cyclohexanone vapor was produced by the vapor saturator, including a temperaturecontrolled heating unit and a thermal desorption column [19]. The thermal desorption column was a stainless steel tube (SS316, o.d. $6.33 \mathrm{~mm}, 0.43 \mathrm{~m}$ long) with $6 \mathrm{~mL} 102$ pickling silanized white carrier (60-80 mesh size) inside. About $4-5 \mathrm{~cm}$ of loose glass wool was plugged at both ends of the column to prevent the carrier powder from flowing out. The valves at both end of the column were used to control the inflow of cyclohexanone; when the valves were opened, the cyclohexanone vapor was carried to the reactor for the adsorption experiment. The bypass allows the carrier gas to enter the reactor directly, without passing through the vapor generator. The outlet line was heated to $100{ }^{\circ} \mathrm{C}$ to prevent cyclohexanone from condensing during transfer.

\subsection{Experiment Procedure}

Before the experiment, to obtain a uniform water film more easily, the quartz boat was covered with $5 \mathrm{~mL} \mathrm{NaOH}(50 \mathrm{wt} \%)$ for $1 \mathrm{~h}$. After rinsing off the boat with a large amount of deionized water, a known amount of deionized water was added to it for film formation. The thermal desorption column injected with $0.25 \mathrm{~mL}$ of cyclohexanone was used for vapor generation. Gas chromatography (GC) was used to record the cyclohexanone signal. It took a few hours for the steam and water film to reach the partition equilibrium. When the GC peak height reached a plateau, the adsorption was completed. Water film in the reactor was collected for liquid-chromatography analysis. Before starting the next experiment, the carrier was switched to bypass and the whole equipment was purged to avoid residue.

In this work, the stability of this instrument was confirmed by a series of blank experiments using the boat without any water film. After that, the effects of water film thickness (102-1020 $\mu \mathrm{m})$ and temperature (278-296 K) on the partition equilibrium of cyclohexanone were investigated. The same humidified carrier gas was used in these experiments.

\subsection{Analysis}

The analysis of cyclohexanone was performed on a 3420A gas chromatograph (Beijing Beifen-Ruili Analytical instrument, Beijing, China) equipped with a flame ionization detector (FID). An SE-54 column $(1 \mathrm{~m} \times 3 \mathrm{~mm})$ was used for separation. A 6-port injection valve (Valco Instrument, Houston, TX, USA) and a digital valve sequence programmer were connected to the GC for automatic gas-phase sample injection every $6 \mathrm{~min}$.

An ultra-performance liquid chromatography (UPLC, LC-30AD, Shimadzu Corporation, Kyoto, Japan) equipped with a diode-array detector was used to quantify cyclohex- 
anone in the aqueous film samples. An ultra-aqueous C18 column $(2.1 \times 100 \mathrm{~mm}, 3 \mu \mathrm{m})$ was used for separation. The mobile phase was methanol and deionized water (60:40). The detection wavelength was set to $273 \mathrm{~nm}$ [20]. The injection volume was $2 \mu \mathrm{L}$, and the column thermostat was set to $20^{\circ} \mathrm{C}$.

\section{Results and Discussion}

\subsection{Quality Control}

In order to ensure the accuracy of the method for the adsorption of gas-phase cyclohexanone and the proper interpretation of the results, appropriate quality control (QC) of the experiments was necessary. The reliability of the measured interfacial partition constant depended on the confidence in the results.

The blank experiment using an empty thermal desorption column was first performed to monitor the temperature and humidity in the flow-tube reactor system. Figure 2 shows the stability of temperature and humidity. All points were determined twice, and the estimated error in this test was between $0.5 \%$ and $1 \%$ for temperature and humidity, respectively.

Figure 3 shows the chromatogram of a blank experiment conducted with cyclohexanone vapor passing through it. The signal of cyclohexanone can be continuously collected by automatic injection, and the concentration of cyclohexanone in the carrier gas was able to be quantified. The time interval of similar peaks is $6 \mathrm{~min}$. The embedded figure in Figure 3 shows the chromatogram for a single injection of cyclohexanone.

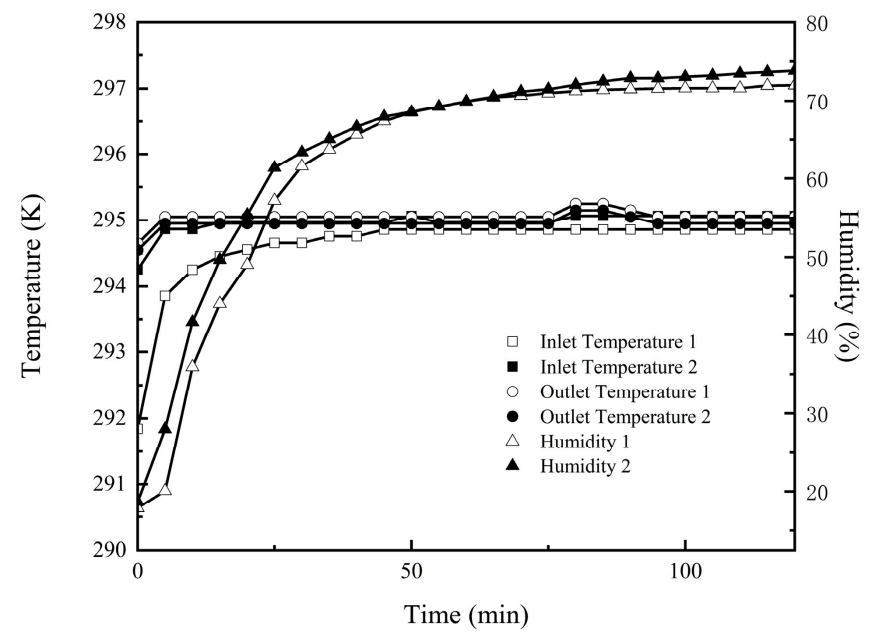

Figure 2. Temperature and humidity stability of the flow-tube reactor system.

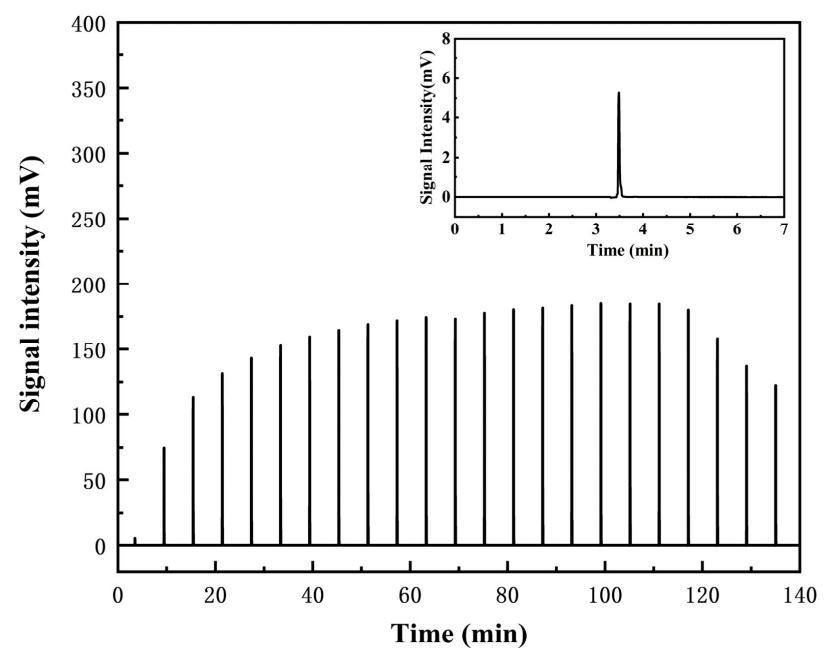

Figure 3. Chromatogram of automatic injection of gas-phase cyclohexanone. 


\subsection{Interfacial Partition Constant of Cyclohexanone}

The uptake experiments were conducted at $296 \mathrm{~K}$. The water film thickness ranged from 102 to $1020 \mu \mathrm{m}$. The bottom surface area of the glass boat is $147 \mathrm{~cm}^{2}$ and was fully coated with the water film. The thickness of the film was controlled by the volume of water added.

Figure 4 shows the variation of the overall equilibrium concentration of cyclohexanone in the aqueous film with the inverse of the film thickness at $296 \mathrm{~K}$. The cyclohexanone concentration was plotted as a function of the inverse of film thickness to determine the partitioning constants. With the increase in film thickness, the overall equilibrium concentration of cyclohexanone in the aqueous film decreased. On the contrary, surface adsorption became the dominant partition mechanism as the film thickness decreased. The correlation coefficient of the linear fit was 0.9932 , indicating a good correlation between the two parameters. According to Equation (1), the y-axis intercept and slope of the curve are the values of bulk phase concentration $\left(\mathrm{C}_{\mathrm{W}}\right)$ and $\mathrm{K}_{\mathrm{AI}} \cdot \mathrm{C}_{\mathrm{g}}$, respectively. In combination with the cyclohexanone concentration $\left(\mathrm{C}_{\mathrm{g}}\right)$ determined by $\mathrm{GC}$, the interfacial partition constant $\mathrm{K}_{\mathrm{AI}}$ and the bulk phase partition constant $\mathrm{K}_{\mathrm{wa}}$ were obtained.

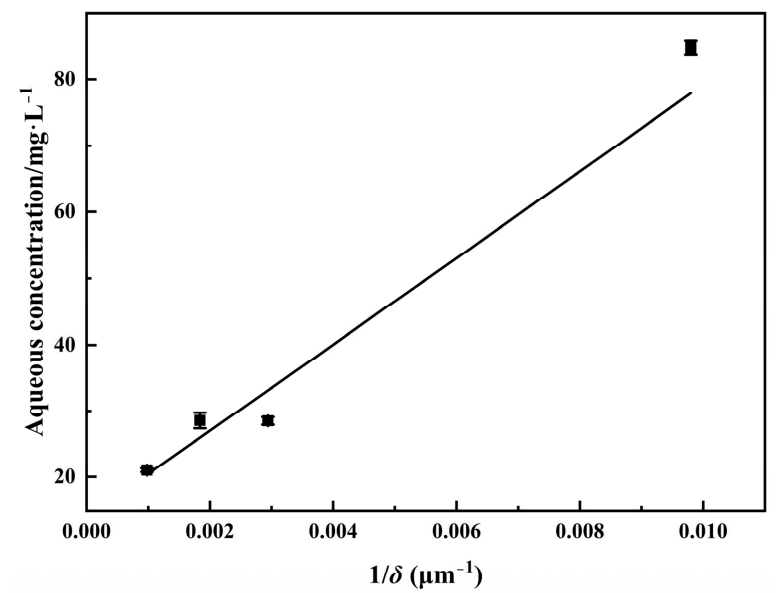

Figure 4. Uptake of cyclohexanone from the gas-phase on water films with varying thicknesses.

As shown in Table 1, the average gas-phase concentration for different water film experiments was $2.56 \mathrm{mg} \cdot \mathrm{L}^{-1}$ with a relative standard deviation of $4.33 \%$. The overall concentrations of cyclohexanone in water film determined by UPLC ranged from 19.92 to $80.22 \mathrm{mg} \cdot \mathrm{L}^{-1}$. The concentration decreased with increasing film thickness. The interfacial partition constant $\mathrm{K}_{\mathrm{AI}}$ at $296 \mathrm{~K}$ is 2107.52 . Based on the value of $\mathrm{K}_{\mathrm{AI}}$, when the thickness of the aqueous film was less than $437 \mu \mathrm{m}$, the concentration of cyclohexanone in the aqueous film $\left(\mathrm{K}_{\mathrm{AI}} \cdot \mathrm{C}_{\mathrm{g}} / \delta\right)$ was all higher than that in bulk water $\left(\mathrm{C}_{\mathrm{W}}\right)$.

Table 1. Bulk and interface air-water partition constants of cyclohexanone.

\begin{tabular}{cccccc}
\hline Thickness $/(\mu \mathrm{m})$ & $\mathbf{C}_{\mathbf{g}} /\left(\mathbf{m g} \cdot \mathbf{L}^{-\mathbf{1}}\right)^{\mathbf{a}}$ & $\mathbf{C}_{\mathbf{w}}^{\mathbf{T}} /\left(\mathbf{m g} \cdot \mathbf{L}^{-1}\right)$ & $\mathbf{K}_{\mathbf{w a}}$ & $\mathbf{C}_{\mathbf{w}} /\left(\mathbf{m g} \cdot \mathbf{L}^{-\mathbf{1}}\right)^{\mathbf{b}}$ & $\mathbf{K}_{\mathrm{AI}} /(\mu \mathbf{m})$ \\
\hline 102 & & 80.22 & & & \\
340 & 2.56 & 26.99 & & & \\
544 & $(\mathrm{RSD}=4.33 \%)$ & 27.02 & 4.57 & $12.33 \pm 3.31$ & $2107.52 \pm 234.80$ \\
1020 & & 19.92 & & & \\
\hline
\end{tabular}

${ }^{\mathrm{a}}$ The $\mathrm{C}_{\mathrm{g}}$ value is the average gas-phase concentration for different water film experiments. ${ }^{\mathrm{b}}$ Uncertainties for $\mathrm{C}_{\mathrm{W}}, \mathrm{K}_{\mathrm{AI}}$ were based on the standard errors for the linear regression as shown in Figure 4.

\subsection{The Effect of Temperature on the Uptake of Cyclohexanone into the Water Film}

The relationship between partition and temperature can be described by the van't Hoff equation:

$$
\ln \mathrm{K}_{\mathrm{Wa}}^{*}=-\frac{\Delta_{\mathrm{g} \rightarrow \mathrm{w}} \mathrm{H}}{\mathrm{R}} \cdot \frac{1}{\mathrm{~T}}+\frac{\Delta_{\mathrm{g} \rightarrow \mathrm{w}} \mathrm{S}}{\mathrm{R}}
$$


The effect of temperature on $\ln K_{W a}^{*}$ was studied on a $340 \mu \mathrm{m}$ film by varying the temperature from 278 to $296 \mathrm{~K}$. The value of $\ln \mathrm{K}_{W \mathrm{Wa}}^{*}$ was obtained from the overall concentration for cyclohexanone in the film, consisting of the cyclohexanone distributed at the air-water interface and the aqueous phase. Figure 5 shows the value of $\ln \mathrm{K}_{W a}^{*}$ as a function of $1 / \mathrm{T}$. The y-axis intercept and slope of the curve can be converted into $\Delta_{\mathrm{g} \rightarrow \mathrm{w}} \mathrm{H}$ (enthalpy of solvation) and $\Delta_{\mathrm{g} \rightarrow \mathrm{w}} \mathrm{S}$ (entropy of solvation). The experiments were conducted at only one film thickness, which may cause a deviation in the uncertainty of the data. However, according to the mass distribution between the gas-water interface and bulk water, the mass fraction of cyclohexanone in the gas-water interface was $0.37 \%$. At this film thickness, absorption into the bulk phase of the thin film was dominant over the surface adsorption term. The effect of interfacial adsorption on the mass partitioning of cyclohexanone cannot be neglected when $\delta$ is very small. Moreover, the values obtained for $\Delta_{\mathrm{g} \rightarrow \mathrm{w}} \mathrm{H}$ and $\Delta_{\mathrm{g} \rightarrow \mathrm{w}} \mathrm{S}$, were $4.83 \pm 0.47 \mathrm{~kJ} \cdot \mathrm{mol}^{-1}$ and $-13.94 \pm 1.65 \mathrm{~J} \cdot \mathrm{mol}^{-1}$, respectively (uncertainties for $\Delta_{\mathrm{g} \rightarrow \mathrm{w}}$ H and $\Delta_{\mathrm{g} \rightarrow \mathrm{w}} \mathrm{S}$ were based on standard errors for the linear regression, as shown in Figure 5).

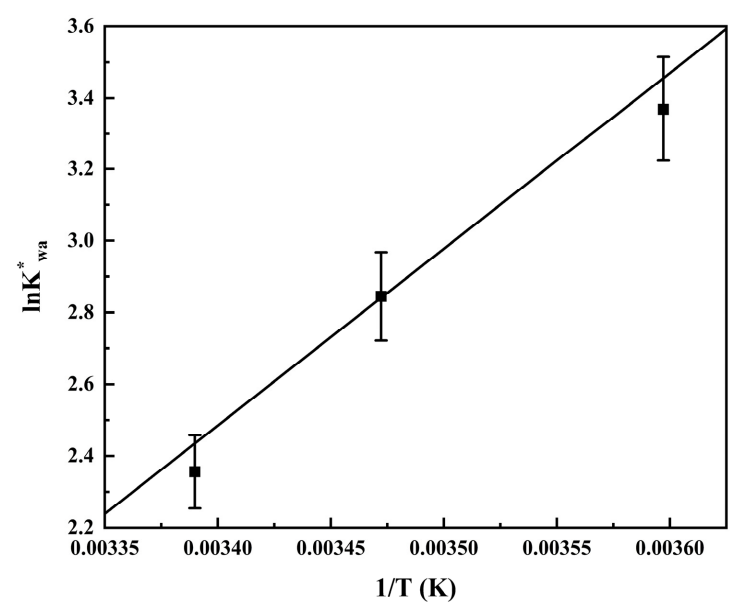

Figure 5. Uptake of cyclohexanone from the gas phase on water films at different temperatures.

\section{Conclusions}

In this work, a new flow-tube reactor technique was developed. This reactor technique is very reliable, quick, and completely automatic. It provides a simple, straightforward procedure to measure the partitioning behavior for cyclohexanone in thin films. The airwater interfacial partition constant at $296 \mathrm{~K}$, and the relevant thermodynamic parameters were obtained. The value of $\mathrm{K}_{\mathrm{AI}}$ was 2107.52. The enthalpy of cyclohexanone uptake in thin water film was $4.83 \pm 0.47 \mathrm{~kJ} \cdot \mathrm{mol}^{-1}$, and the entropy was $-13.94 \pm 1.65 \mathrm{~J} \cdot \mathrm{mol}^{-1}$.

Surface adsorption became the dominant absorption mechanism for cyclohexanone as the film thickness decreased. As far as we know, the values of air-water interfacial partition constant of cyclohexanone presented in this paper are the first values based on experimental data. The study of gas-phase cyclohexanone partitioning on atmospheric water films has the potential to provide insight into the processing of cyclohexanone by atmospheric aerosols and droplets.

Author Contributions: Conceptualization and design, H.W.; methodology, S.H.; writing-original draft preparation, S.H., C.S.; data analysis, Y.Z., W.Z.; manuscript-review and editing, X.W. and J.L. All authors have read and agreed to the published version of the manuscript.

Funding: This research was funded by the National Natural Science Foundation of China (Grant No. 21876202, 21177158, 61674172), the National Key Research and Development Program of China (Grant No. 2021YFB3301102).

Institutional Review Board Statement: Not applicable.

Informed Consent Statement: Not applicable. 
Conflicts of Interest: The authors declare no conflict of interest. The funders had no role in the design of the study; in the collection, analyses, or interpretation of data; in the writing of the manuscript, or in the decision to publish the results.

\section{References}

1. Greener, Y.; Martis, L.; Indacochea-Redmond, N. Assessment of the toxicity of cyclohexanone administered intravenously to Wistar and Gunn rats. J. Toxicol. Environ. Health 1982, 10, 385-396. [CrossRef] [PubMed]

2. Pei, Y.; Shen, B.; Lei, F.; Gong, X.; Wang, Q. Distribution of cyclohexanol and cyclohexanone between water and cyclohexane. Fluid Phase Equilib. 2015, 20, 429-437. [CrossRef]

3. Ong, C.N.; Sia, G.L.; Chia, S.E.; Phoon, W.H.; Tan, K.T. Determination of cyclohexanol in urine and its use in environmental monitoring of cyclohexanone exposure. J. Anal. Toxicol. 1991, 15, 13-16. [CrossRef] [PubMed]

4. Bembea, M.M.; Ng, D.K.; Carroll, M.; Roem, J.L.; Groopman, J.; Caprarola, S.D.; Schwartz, J.M.; Felling, R.J.; Salorio, C.F.; Ellis, G. Cyclohexanone exposure in children on extracorporeal membrane oxygenation support. ASAIO. J 2021. online first. [CrossRef] [PubMed]

5. Cui, R.; Ma, Y. Characteristics of volatile organic compounds (VOCs) emission from electronic products processing and manufacturing factory. China Environ. Sci. 2013, 34, 4585-4591.

6. $\quad$ Liang, X.; Zhang, J.; Chen, X.; Shi, T.; Sun, X.; Fan, L.; Ye, D. Reactivity-based anthropogenic VOCs emission inventory in China. China Environ. Sci. 2017, 38, 845-854.

7. Zhou, Y.; Yao, L.; Zhang, L.; Wang, T.; Wang, W.; Huang, H. Research on VOCs chemical species profile of major industries based on chemical mechanisms in Tianjin. China Environ. Sci. 2018, 38, 2451-2460.

8. Wang, H.; Niu, L.; Li, J.; Wang, Y.; Wang, G.; Wang, J.; Hao, Z. Characterization and assessment of volatile organic compounds (VOCs) emissions from typical industries. Chin. Sci. Bull. 2012, 57, 1739-1746. [CrossRef]

9. Kabo, G.J.; Yursha, I.A.; Frenkel, M.L.; Poleshchuk, P.A.; Fedoseenko, V.I.; Ladutko, A.I. Thermodynamic properties of cyclohexanol and cyclohexanone. J. Chem. Thermodyn. 1988, 20, 429-437. [CrossRef]

10. Ghanadzadeh, H.; Ghanadzadeh, A.; Asgharzadeh, S.; Moghadam, M. Measurement and correlation of phase equilibrium data of the mixtures consisting of butyric acid, water, cyclohexanone at different temperatures. J. Chem. Thermodyn. 2012, 47, 288-294. [CrossRef]

11. Donaldson, D.J.; Valsaraj, K.T. Adsorption and reaction of trace gas-phase organic compounds on atmospheric water film surfaces: A critical review. Environ. Sci. Technol. 2010, 44, 865-873. [CrossRef] [PubMed]

12. Clifford, D.; Donaldson, D.J.; Brigante, M.; D'Anna, B.; George, C. Reactive uptake of ozone by chlorophyll at aqueous surfaces. Environ. Sci. Technol. 2008, 42, 1138-1143. [CrossRef] [PubMed]

13. Vacha, R.; Cwiklik, L.; Rezac, J.; Hobza, P.; Jungwirth, P.; Valsaraj, K.; Bahr, S.; Kempter, V. Adsorption of aromatic hydrocarbons and ozone at environmental aqueous surfaces. J. Phys. Chem. A 2008, 112, 4942-4950. [CrossRef] [PubMed]

14. Goss, K.U. The air/surface adsorption equilibrium of organic compounds under ambient conditions. Crit. Rev. Environ. Sci. Technol. 2010, 34, 339-389. [CrossRef]

15. Chen, J.; Ehrenhauser, F.; Liyana-Arachchi, T.P.; Hung, F.R.; Wornat, M.J.; Valsaraj, K.T. Adsorption of gas-phase phenanthrene on atmospheric water and ice films. Polycycl. Aromat. Compd. 2011, 31, 201-226. [CrossRef]

16. Chen, J.; Valsaraj, K.T. Uptake and UV-Photooxidation of gas-phase polyaromatic hydrocarbons on the surface of atmospheric water films. 2. Effects of dissolved surfactants on naphthalene photooxidation. J. Phys. Chem. A 2007, 111, 4289-4296. [CrossRef] [PubMed]

17. Chen, J.; Ehrenhauser, F.S.; Valsaraj, K.T.; Wornat, M.J. Uptake and UV-Photooxidation of gas-phase PAHs on the surface of atmospheric water films. 1. Naphthalene. Phys. Chem. 2006, 110, 9161-9168. [CrossRef] [PubMed]

18. Santanu, P.; Nihar, R.B.; Rajib, G.C. Surface tension, adsorption, and wetting behaviors of natural surfactants on a PTFE surface. AIChE J. 2015, 61, 655-663.

19. Jung, H.; Lee, H.W. Understanding evaporation characteristics of a drop of distilled sulfur mustard (HD) chemical agent from stainless steel and aluminum substrates. J. Hazard. Mater. 2014, 273, 78-84. [CrossRef] [PubMed]

20. Zhou, W.; Hu, B.; Zhao, L.; Liu, Z. Qualitative and quantitative analysis of the by-products in the course of cyclohexone production by hplc-ms/ms. J. Chin. Mass Spectrom. Soc. 2009, 1, 31-35. 